\title{
CDS Evaluation Model with Neural Networks
}

\author{
Eliana Angelini ${ }^{1}$, Alessandro Ludovici ${ }^{1}$ \\ ${ }^{1}$ University "G. d'Annunzio" of Pescara, University "G. d'Annunzio" of Pescara \\ Email: e.angelini@unich.it, a.ludovici1@tin.it
}

Received May $6^{\text {th }}, 2008$; revised December $27^{\text {th }}, 2008$; accepted February $5^{\text {th }}, 2009$.

\begin{abstract}
This paper provides a methodology for valuing credit default swaps (CDS). In these financial instruments a sequence of payments is promised in return for protection against the credit losses in the event of default. Given the widespread use of credit default swaps, one major concern is whether the credit risk has been priced accurately. Credit risk assessment of counterparty is an area of renewed interest due to the present financial crises.

This article proposes a non parametric model for estimating pricing of the CDS, using learning networks, based on the structural approach pioneered by Merton [1] as regards the independent variables; he proposed a model for assessing the credit risk of a company by characterizing the company's equity as a call option on its assets. The model that we are introducing turns out peculiar not only for the use of the neural network, but also for the use of the implied volatility of one-year options written on the shares of the analyzed companies, instead of historical volatility: this leads to a higher capability of getting the signals launched by the market about the future creditworthiness of the firm (historic volatility, being a medium value, brings in temporal lags in the evaluation). Besides, our analysis differs from the structural approach for the fact that it considers the 30-month mean-reverting historical series for CDS spreads, and this turns out to be one of the main advantages of our forward-looking model.
\end{abstract}

Keywords: credit derivatives, CDS, neural networks, pricing models, credit spreads, implied volatility

\section{Introduction}

In recent years, the market for credit derivatives has expanded dramatically. Credit derivatives are flexible and efficient instruments that enable users to isolate and trade credit risk. Credit derivatives allow users to isolate credit risk from other quantitative and qualitative factors associated with owing an exposure. Hence, they can be used to transfer and hedge credit risk in an efficient and flexible manner, customized to a client's requirements. This transfer of credit risk may be complete or partial, and may be for the life of the asset or for a shorter period. Credit risk includes not just default or insolvency risk but also changes in credit spreads and thereby market values, changes in credit ratings and generic changes in credit quality. Credit derivatives can be used when a sale in the cash market is either not efficient or not possible. Even when cash market alternatives exist, credit derivatives may be preferred because they do not require funding. Furthermore, since derivatives are over-the-counter contracts, transactions are confidential. Finally, speed of settlement and liquidity are reasons why credit derivatives are a better alternative to the reinsurance market. Credit derivatives are swaps, forward and option contracts, particularly credit default swaps (CDS); they can be used to hedge against all these types of credit risk. For a simple credit default swap, over some time period, one counterparty (the protection seller) receives a predetermined fee payment from another counterparty (the protection buyer); in return, the protection seller agrees that in the case of a credit event of a reference entity, it will pay the seller the loss on a bond of the reference entity, that is the bond's par value less its recovery.

Nowadays, banks, corporate, hedge funds, insurance companies and pension funds are hugely exposed as buyers or sellers, or both. By transferring the risk, the CDS have acted as a kind of insurance and provided incentives for risk-taking. They are therefore at the heart of the present crisis.

Given the widespread use of credit default swaps, as an investment or a risk management tool, one major concern is whether the credit risk has been priced accurately. This article proposes a non parametric model for estimating pricing of these credit derivatives, using learning networks. The recent application of nonlinear methods, such as neural networks to credit risk analysis, shows promise of improving on traditional credit models. Neural networks differ from classical credit systems mainly in their black box nature and because they assume a non-linear relation among variables. The two main issues to be defined in a neural network application are the network typology and structure and the learning algorithm. The connections (links) among neurons have an associated weight which determines the type and intensity of the information exchanged. As regards the independent vari- 
ables of the model, we start from the typical assumption of the structural approach based on the theoretical foundation of Merton's [1] option pricing model: the relevant information in order to evaluate credit risk can be obtained from the market data of the analyzed companies. The model developed by Merton views a firm's equity as an option on the firm (held by the shareholders) to either repay the debt of the firm when it is due, or abandon the firm without paying the obligations. What makes that model successful is its reliance on the equity market as an indicator, since it can be argued that the market capitalization of the firm (together with the firm's liabilities) reflect the solvency of the firm. Therefore, option pricing theory is used in order to create a link between the credit market and the securities market. The model that we are introducing turns out peculiar not only for the use of neural networks, but also for the use of the implied volatility of one-year options written on the shares of the companies, instead of historical volatility: this leads to a higher capability of getting the signals launched by the market about the creditworthiness of the firm (historical volatility, being a medium value, brings in temporal lags in the evaluation). Besides, our analysis differ from the structural approach for the fact that it consider the 30-month historical series for CDS spreads, and this turns out to be one of the main advantage of our forwardlooking model.

The paper is organized as follows. The paper begins, in Section 1, by stating the implications of credit derivatives in portfolio credit risk management. In Section 2, we first briefly overview the main principles and characteristics of neural networks, focusing the attention above all on the concepts that are most useful for the application to financial instruments; then we describe the pricing model we developed and tested for credit derivatives. Section 3 develops the theory underlying our implementation of Merton's model. Section 4 describes the data and we present our results: the effectiveness of neural network in approximating the evaluation of credit default swap is illustrated. As regards the sample, it includes 18 American firms, relative to various fields, including financial institutions which, operating typically with a high leverage due both to the activity carried out and to the laws concerning the capital of banks, usually introduces remarkable factors of distortion in parametric models. We shall show that neural networks are not affected by this problem. The temporal range embraces the period September 2002-March 2006: we have considered the fiveyear CDS spread relative to each firm, for a total of 180 observations on a quarterly basis obtained through the Fitch $^{\mathrm{TM}}$ database. As already pointed out, implied volatility has a determining role among the variables; in fact we have obtained a positive correlation with CDS spreads equal to 0.6338 . Leverage is another key variable, obtained dividing the face value of the debt of the firm by the total of its liabilities (including the market capitalization),

\footnotetext{
${ }^{1}$ The credit default swap is also known as credit default put, credit swap default swap, credit put or default put.
}

getting the data from the Bloomberg ${ }^{\mathrm{TM}}$ database. We have considered the risk free rate equal to one-year constant maturity Treasury Bills yield, taken from the Federal Reserve System database. We then discuss in detail the experimental settings and the results we obtained, leading to considerable accuracy in prediction. The architecture of the neural network is feed-forward, trained for 17000 learning epochs using the back-propagation algorithm, with two hidden layers of 9 and 10 neurons each: by the study carried out it turns out obvious that neural networks are able to totally capture the variability relative to the market dynamics of credit default swap. The paper ends evidencing that, as far as this field of the financial markets is concerned, neural networks constitute a highly valid instrument of calculation: in fact there still does not exist in literature a formula of evaluation for the CDS, able to tie the quoted spreads to the specific underlying variables of each examined firm, and the neural network can, as will be shown, satisfy this lack with high effectiveness, facing the problem of determination of the functional form from a statistical point of view. As we will show, it is easy to calculate the sensitivity of the CDS spread to each independent variable, in order to determine a statistical pricing formula for CDS.

The paper concludes with a discussion of advantages and limitations of the solution achieved.

\section{Credit Derivatives: Innovative Financial Instruments}

Credit derivatives are financial instruments used to transfer credit risk of loans and other assets. They are bilateral financial contracts with payoffs linked to a credit related event such as a default, credit downgrade or bankruptcy. There are various types, but the basic structures of all credit derivatives are swaps, options and forwards. Due to their high flexibility credit derivatives can be structured according to the end-users' needs. For instance, the transfer of credit risk can be effected to the whole life of the underlying asset or for a shorter time, and the transfer can be a complete or a partial one. Delivery can take place in the form of over the counter contracts or embedded in notes. Moreover, the underlying can consist of a single credit-sensitive asset or a pool of credit-sensitive assets [2].

\subsection{Credit Derivatives: Products and Structures}

The most important and widely used credit derivative is a credit default swap ${ }^{1}$. It is an agreement in which the one counterparty (the protection buyer) pays a periodic fee, typically expressed in fixed basis points on the notional amount, in return for a contingent payment to the other counterparty (the protection seller) in the event that a third-party reference credit defaults. A default is strictly defined in the contract to include, for example, bankruptcy, insolvency, and/or payment default. The definition of a credit event, the relevant obligations and the settlement mechanism used to determine the contingent payment are flexible and determined by negotiation between the 
counterparties at the inception of the transaction. Since 1991, the International swap and Derivatives association (ISDA) has made available a standardized letter confirmation allowing dealers to transact credit swaps under the umbrella of an ISDA Master Agreement. The evolution of increasingly standardized terms in the credit derivatives market has been a major growth because it has reduced legal uncertainty that hampered the market's growth.

The contingent payment in the event of default can be identified as either:

- a payment of par by the protection seller in exchange for physical delivery of the defaulted underlying;

-a payment of par less the recovery value of the underlying as obtained from dealers;

- a payment of a binary, i.e. fixed, amount.

Credit default swaps can be viewed as an insurance against the default of the underlying or a put option on the underlying. Figure 1 exhibits the basic structure of a credit default swap.

Moreover, there is the total return swap, in which one counterparty (total return payer) pays the other counterparty (total return receiver) the total return of an asset (the reference obligation) for receiving a regular floating rate payment, such as Libor plus a spread. "Total return" comprises the sum of interest, fees and any change-in value payments (any appreciation or depreciation) with respect to the reference obligation.

In contrast to the credit default swap, the total return swap does not only transfer the credit risk but also the market risk of the underlying; it effectively creates a synthetic credit-sensitive instrument. A total return swap allows an investor to enjoy all of the cash flow benefits of a security without actually owing the security.

Credit spread option is an option on a reference credit's spread in the loan or bond market. In a spread put option one party pays a premium for the right to sell a bond to a counterparty at a certain spread at a definite time in the future. A credit spread option gives the buyer protection in the event of any unfavourable credit migration. In a default option, the asset can be put only on default. The credit spread is the differential yield between the reference credit and a pre-determined benchmark rate. Thus, in credit spread derivatives, payment is based on the movement of the value of one reference credit against another.

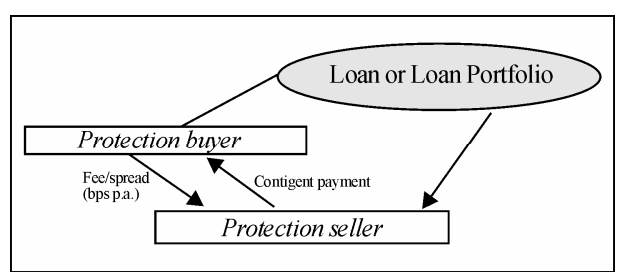

Figure 1. Credit default swap

\footnotetext{
${ }^{2}$ For more detailed information on the characteristics of credit derivatives see DAS, S., (1998); TAVAKOLI, J.M., (1998).
}

that pays out if a specified company's rating is downgraded. This kind of option is sometimes embedded in bond structures.

Finally, credit linked notes are created by embedding credit derivatives in notes. Credit derivatives have the advantage that funding is not necessary; whereas credit linked notes have the benefit of avoiding counterparty risk. Credit linked notes are frequently issued by special purpose vehicles (corporations or trusts) that hold some form of collateral securities financed through the issuance of notes or certificates to the investor. The investor receives a coupon and par redemption, provided there has been no credit event of the reference entity. The vehicle enters into a credit swap with a third party in which it sells default protection in return for a premium that subsidizes the coupon to compensate the investor for the reference entity default risk.

\subsection{Fundamental Attractions of Using Credit Derivatives}

In theory, credit derivatives are tools that enable financial operators to manage their portfolio of credit risks more efficiently; they enable market participants to devise flexible personal approaches to the management of credit risk associated with a variety of underlying financial assets. The promise of these important instruments has not escaped regulators and policymakers. "Credit derivatives and other complex financial instruments have contributed to the development of a far more flexible, efficient, and hence resilient financial system than existed just a quarter-century ago" [3].

The credit derivatives market offers its users a range of tools which enable the transfer of credit risk. A brief review of the available products reveals that in most cases one party to a transaction receives a fee and commits to provide the other party with a payment should the credit quality of a third party deteriorate. Whilst the mechanism contained in these products are easy to understand, the broad range of applications is not immediately obvious.

The users of the risk-management benefits of credit derivatives tend to be quite diverse. An increasingly important user group includes financial institutions, corporate and fund managers. Financial institutions have embraced the full range of benefits; the use of credit derivatives by banks has been motivated by the desire to improve portfolio diversification and to improve the management of credit portfolios. Corporate is also looking to reduce the credit exposure to key trading partners and specifically they are interested in using credit derivatives to isolate credit risks in project financing. For fund managers, although the asset benefits of credit derivatives still suffer from lack of liquidity, the use of structures that hedge out spread risk has some appeal.

This paragraph focuses on a range of uses for credit derivatives and divides them between credit risk management and asset opportunities ${ }^{2}[4,5]$. 


\subsubsection{Using Credit Derivatives for Managing Credit Risk} The principal feature of these instruments is that they separate and isolate credit risk facilitating the trading of credit risk with the purpose of:

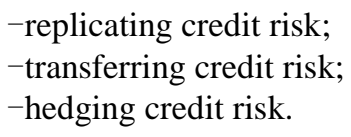

In practice, the rationale behind a transaction may relate to the management of credit lines, to regulatory capital offsets, to balance sheet optimization, portfolio hedging and diversification or pure risk reduction itself. Credit derivatives can be used as a risk management tool by portfolio managers to:

-Achieve portfolio diversification: credit derivatives can be used to achieve portfolio diversification by allowing access to previously unavailable credits. They can also be used to diversify across a range of borrowers and to gain exposure to an asset without owing it.

-Reduce concentration risk: investors can reduce portfolio credit risk concentrations using derivatives structures; they can thus manage country and industry risks. Reducing credit concentration in loan portfolios is commonly viewed as the main use of credit derivatives. However, to date credit derivatives are generally referenced to assets which are widely traded, i.e. for which market prices are readily available, or for which a rating by an international agency is at hand.

-Manage exposures while maintaining client relationships. Changes to credit risk management in the banking sector are an additional factor contributing to greater use of credit derivatives. Investors can use credit derivatives to reduce exposures without selling them. This effectively frees up credit lines, allowing more business to be done with a customer. Furthermore, a bank that is concerned about credit loss on a particular loan can protect itself by transferring the risk to someone else while keeping the loan on its books. As part of their credit risk management, banks are viewing credit derivatives more and more often as tradable products, which can be transferred to third parties before the maturity date $[6,7,8]$.

-Manage regulatory capital: the new supervisory rules provided for by Basel II are also increasing the incentives for banks to use credit derivatives. Where guarantees or credit derivatives are direct, explicit, irrevocable and unconditional, and supervisors are satisfied that banks fulfil certain minimum operational conditions relating to risk management processes, they may allow banks to take account of such credit protection in calculating capital requirements. A guarantee or credit derivative must represent a direct claim on the protection provider and must be explicitly referenced to specific exposures or a pool of exposures, so that the extent of the cover is clearly defined and incontrovertible. Other than non-payment by a protection purchaser of money due in respect of the credit protection contract it must be irrevocable; there must be no clause in the contract that would allow the protection provider unilaterally to cancel the credit cover or that would increase the effective cost of cover as a result of deteriorating credit quality in the hedged exposure. It must also be unconditional; there should be no clause in the protection contract outside the direct control of the bank that could prevent the protection provider from being obliged to pay out in a timely manner in the event that the original counterparty fails to make the payment due. There are cases where a bank obtains credit protection for a basket of reference names and where the first default among the reference names triggers the credit protection and the credit event also terminates the contract. In this case, the bank may recognise regulatory capital relief for the asset within the basket with the lowest risk-weighted amount, but only if the notional amount is less than or equal to the notional amount of the credit derivative. In the case where the second default among the assets within the basket triggers the credit protection, the bank obtaining credit protection through such a product will only be able to recognise any capital relief if first-default-protection has also be obtained or when one of the assets within the basket has already defaulted [9].

\subsubsection{Asset Opportunities}

Credit derivatives have evolved to become an important financial asset class. As already argued, credit derivatives enable credit risk to be separated from the funding component of its underlying instrument; as it is often the form of the underlying instrument that creates obstacles for the investor, this separation of the credit risk creates important opportunities. The decision to use the asset opportunities of credit derivatives tends to be based on one of the following needs:

-Access to new markets: investors can create new assets with a specific maturity not currently available in the market;

-Obtain tailored investments: credit derivatives can be used to create instruments with exact risk- return profile sought. Maintaining diversity in credit portfolios can be challenging. This is particularly true when the portfolio manager has to submit with constraints such as currency denominations, listing considerations or maximum or minimum portfolio duration. Credit derivatives are being used to address this problem by providing tailored exposure to credits that are not otherwise available in the wished form or not available at all in the cash market.

-Improve the risk-return profile of portfolios: credit derivatives offer new possibilities of turning a given market opinion into an investment strategy. This particularly entails assumption of specific types of 
credit risk without the acquisition of the asset itself. Instead of purchasing a specific bond, a market participant who considers some credit risks to be overvalued can earn an attractive premium as a protection seller in the credit default swap market. Premiums are generated without having to tie up any capital for the purchase of a bond issue (at least as long as no credit event occurs). On the other hand, market participants who consider risks to be underestimated can purchase protection by paying a premium. Owing to the limited possibilities for short sales in the bond market, hedge funds are increasingly entering into positions in credit derivative market to implement their financial strategies. In particular:

- to hedge dynamic risks: exposures that change with market movements can be hedged using credit derivatives;

- to manage illiquid credits: credit derivatives can be utilized to actively manage risk in large illiquid loans portfolios;

- to execute short credit positions: credit derivatives can be employed to execute short credit positions without the risk of a short squeeze or high financing costs. Hence, investors can use them to hedge or take advantage of deteriorating credit qualities;

- to hedge declining credit quality: default and spread options and swaps can be used to hedge failing credit qualities. Credit spread options and swaps can be used to hedge fluctuations in credit spreads without having to wait for default to get a payout.

\section{The Neural Network Model}

The general structure of a neural network model consists of simple processing units called nodes that interact with each other using weighted connections. Each unit (node) receives and processes inputs, and delivers a single output. The input can be raw or output of other processing units. The output can be the final product or an input to another unit. In processing the inputs, the model assigns a weight to each input, where weights represent the relative strength or importance of inputs. A neural net essentially represents a nonlinear discriminant function as a pattern of connections between its processing units.

Neural networks have been used in different fields of study, such as engineering, medicine, physics and others. Although the relative structures differ remarkably with one another, it is possible to point out some fundamental principles regarding essentially the functioning of such operative instruments. Moreover, it is important to start the treatment emphasizing that, in order to analyze the financial dynamics, relatively little complex networks are

\footnotetext{
3 DOLCINO, F., GIANNINI, C., ROSSI, E., (1998). For a useful description of the phenomenon in general terms, see FLOREANO, D., NOLFI, S., (1993) and GORI, M., (2003).

${ }^{4}$ Such feature is important for financial analysis because several studies have shown that the relation between default risk and financial factor (variables) are often non linear. See WU and YU (1996); WU (1991).
}

effective, at least compared to those of other fields ${ }^{3}$ $[10,11,12]$.

Neural networks offer several advantages over the traditional statistical methods. First, neural networks do not require the restrictive assumptions imposed by conventional methodologies. Second, neural networks can develop input-output map boundaries that are highly non linear ${ }^{4}[13,14]$. Third, they have greater fault tolerance and adaptability. Neural network examines all information available and it can incorporate the new information into the analysis promptly through its memorization of previous learning; it updates its weighting scheme so that it continually "learns" from experience. Thus, neural networks are flexible, adaptable systems that can in corporate changing conditions.

\subsection{Architecture of Neural Networks}

A neural network relates a set of input variables $\left\{x_{\mathrm{i}}\right\}$, $i=1,2, . . k$ to a set of one or more output variables $\left\{y_{\mathrm{j}}\right\}$, $j=1,2, . . h$. An essential characteristic of a neural network, differently from other methods of approximation, is that it uses one or more hidden layers, in which the input variables are transformed by a logistic or logsigmoid function: this characteristic, as shown later, gives to these instruments a particular efficiency in modeling nonlinear statistical processes.

In the feed-forward neural network parallel elaboration is associated to the typical sequential elaboration of the linear methods of approximation. In fact while in the sequential elaboration particular weights are given to the input variables through the neurons of the input layer, in the parallel one the neurons of the hidden layer operate further transformations in order to improve the predictions. The connectors (between the input neurons and the neurons in the hidden layers, and between these and the output neurons) are called synapses. The feed-forward neural network with a single hidden layer is the simplest and at the same time the most used network in the economic and financial field.

Therefore the neurons process the input variables in two ways: firstly forming linear combinations and lastly transforming these combinations through a particular function, typically the logsigmoid function, illustrated in

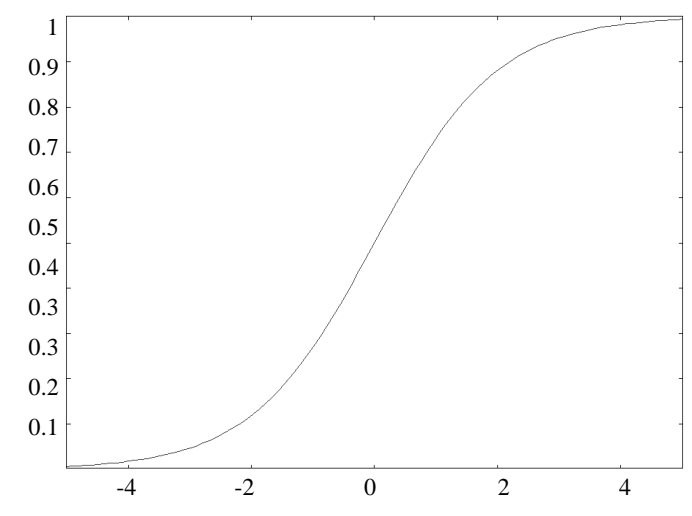

Figure 2. Logsigmoid function 
Figure 2. An essential characteristic of this function is the threshold behavior near values 0 and 1 , which turns out to be particularly suitable to economic problems, which usually, for very high (or very low) values of the independent variables, show little changes in response to small changes of the variables. At the analytical level, the neural network can be described by the following equations [15]:

$$
\begin{aligned}
& n_{k, t}=\omega_{k, 0}+\sum_{i=1}^{m} \omega_{k, i} x_{i, t} \\
& N_{k, t}=L\left(n_{k, t}\right)=\frac{1}{1+e^{-n_{k, t}}} \\
& y_{t}=\gamma_{0}+\sum_{k=1}^{q} \gamma_{k} N_{k, t}
\end{aligned}
$$

where $\mathrm{L}\left(n_{\mathrm{k}, \mathrm{t}}\right)$ represents the logsigmoid activation function. It is a system with $m$ input variables $x_{\mathrm{i}}$ and $q$ neurons. A linear combination of these input variables, observed at time $t$, with the weights of the input neurons $\omega_{\mathrm{k}, \mathrm{i}}$ and the constant term (bias) $\omega_{\mathrm{k}, 0}$ forms the variable $n_{\mathrm{k}, \mathrm{t}}$. Then this variable is transformed by the logistic function and becomes the neuron $\mathrm{N}_{\mathrm{k}, \mathrm{t}}$ at time or observation $t$. The set of $q$ neurons at time or observation $t$ is therefore linearly combined with the coefficient vector $k$ and added to the constant term $\omega_{\mathrm{k}, 0}$ in order to obtain the output $y_{t}$ concerning time or observation $t$, representing the prediction of the neural network for the analyzed variable. The feed forward neural network used with the logsigmoid activation function is often called multi-layer preceptor or MLP network. A highly complex problem could be treated widening this structure, and therefore using two (respectively $\mathrm{N}$ and $\mathrm{P}$ ) or more hidden layers [15]:

$$
\begin{aligned}
& n_{k, t}=\omega_{k, 0}+\sum_{i=1}^{m} \omega_{k, i} x_{i, t} \\
& N_{k, t}=L\left(n_{k, t}\right)=\frac{1}{1+e^{-n_{k, t}}} \\
& \rho_{l, t}=\rho_{l, 0}+\sum_{k=1}^{s} \rho_{l, k} N_{k, t} \\
& \rho_{l, t}=\frac{1}{1+e^{-p_{l, t}}} \\
& y_{t}=\gamma_{0}+\sum_{l=1}^{q} \gamma_{l} P_{l, t}
\end{aligned}
$$

Adding another hidden layer increases the number of parameters (weights) to be estimated by the factor $(s+1)$ $(q-1)+(q+1)$, since the net with a single hidden layer, with $m$ input variables and $s$ neurons has $(m+1) s+(s+1)$ parameters, while the same net with two hidden layers and $q$ neurons in the second hidden layer has $(m+1) s+(s+1) q+$ $(q+1)$ parameters. However the disadvantage of these models for complexity does not consist of the number of parameters, which in any case use up degrees of freedom if the sample size is limited and requires a longer training time, but of the greater probability that the net converges to a local rather than global optimum. Anyway it has been demonstrated that a neural network with two layers is able to approximate any nonlinear function [16]. A further quality of this instrument consists exactly of the fact that it does not just approximate a phenomenon on the basis of a presumed functional form to be adapted, but at the same time it determines the functional form and proceeds to the evaluation of the weights.

In Figure 3 a net with a multiple number of output variables is illustrated. A neural network with a hidden layer and two output variables is described by the following equations:

$$
\begin{aligned}
& n_{k, t}=\omega_{k, 0}+\sum_{i=1}^{m} \omega_{k, i} x_{i, t} \\
& N_{k, t}=L\left(n_{k, t}\right)=\frac{1}{1+e^{-n_{k, t}}} \\
& y_{1, t}=\gamma_{1,0}+\sum_{k=1}^{q} \gamma_{1, k} N_{k, t} \\
& y_{2, t}=\gamma_{2,0}+\sum_{k=1}^{q} \gamma_{2, k} N_{k, t}
\end{aligned}
$$

It is possible to observe that adding an output variable implies the evaluation of $(q+1)$ parameters more, equal to the number of neurons of the hidden layer increased of one unit. Therefore adding an output variable implies an increasing number of parameters to be estimated, equal to the number of the neurons of the hidden layer, not to the input variables. Using a neural network with multiple outputs makes sense only if these are closely correlated to the same set of input variables: as an example we could mention the temporal structure of the rates of inflation or of the rates of interest. One of the most common criticisms made to these instruments is that they are substantially black boxes: questions regarding the nature of the parameters, the reasons of the choice of their number, of

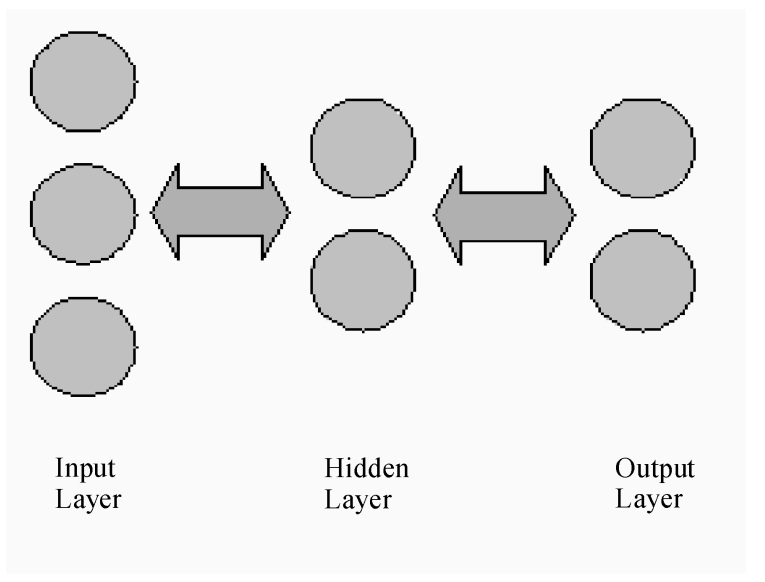

Figure 3. Neural network with one hidden layer and two output neurons 
the number of the neurons, of the number of the hidden layers, the reasons that relate the architecture of the net to the structure of the underlying problem to be explained do not find an answer.

The risk, when models are based on a high number of parameters, is that their extreme flexibility [17], being able to explain anything and its opposite, ends up in not carrying any knowledge contribution. However, we must underline that the same criticism can be made to any statistical approximation method: therefore not only to neural networks, but also to linear models, univariate and multivariate regression and so on. Neural networks, in particular, are able to explain very irregular processes, on which it is therefore difficult to identify a precise relation of cause-effect. Therefore the black box criticism constitutes, paradoxically, also one of the greatest qualities of neural networks. In any case, the simplicity with which it is possible to increase the number of the parameters of the net must never make forget the importance, in any model, of the clarity of the assumptions.

\subsection{Data Scaling}

A neural network is not able to analyze data or to give solutions in absolute value: especially if there are data of an unusually elevated or reduced value, problems of overflow or underflow could happen. When instead sigmoid functions are used, it becomes indispensable to preprocess data: this family of functions in fact has a codominy of type $[0,1]$ (or $[-1,1]$ in the case of the logsigmoid function), for which the values must be scaled to these intervals otherwise the output of the net would become useless, being equal to the superior or inferior threshold in correspondence of all the different values higher or lower than a determined limit. In other words, for a great amount of data not standardize to the interval the neurons would simply transmit the threshold value, so a wide part of the information would be lost. As far as the methods, the linear reduction transforms the series of values $x_{k}$ in the series $\hat{\mathrm{x}}_{\mathrm{k}} x_{k}$, using the following formulas:

$$
\hat{x}_{k, t}=\frac{x_{k, t}-\min \left(x_{k}\right)}{\max \left(x_{k}\right)-\min \left(x_{k}\right)}
$$

if the range is between 0 and 1 , and

$$
\hat{x}_{k, t}=2 \frac{x_{k, t}-\min \left(x_{k}\right)}{\max \left(x_{k}\right)-\min \left(x_{k}\right)}-1
$$

if the desired range is between -1 and 1 , while the logarithmic reduction uses the formula:

$$
\hat{x}_{k, t}=\frac{\log \left(1+x_{k, t}\right)}{\log \left(\max \left(x_{k}\right)\right)}
$$

\subsection{Learning Process}

After the data have been scaled, we have to deal with the problem of the evaluation of the parameters (weights) through the process known as learning (training) of the neural network. Certainly it is a much more complex problem than the evaluation of the parameters of a linear model, as for the nature of high nonlinear complexity of neural networks. For these reasons numerous optimal solutions can exist, but they do not minimize the difference between the predictions of the net and the effective values to be evaluated. In short, in any non linear model it is necessary to begin the evaluation of the parameters on the basis of conditions which represent a guess of the value of the same. However, as it will be shown, the capability of the process of evaluation of the parameters to converge to a global optimum depends on the goodness of these initial hypothesis: in fact if it is situated near a local optimum instead of the global one [10], it is likely that the first one will be reached.

This is illustrated in Figure 3: the initial guess of the parameters (or weights of the neurons) could accidentally be situated wherever on the X-axis: if it is near a local minimum, the training process of the net would lead towards this. Later on, it will be observed that the training process of the network is completed when a point is reached in which the derivative of the loss function is null: we must remember that this condition, beyond the global optimum, identifies also the local ones and the saddle points. So it can be anticipated that if the learning coefficient, which indicates the sensibility of the net to the training process, is too low, this would lead to the impossibility of the network to escape from local optimums; while if it is too high, it could carry the training process to oscillate continuously far away from the optimum point, and therefore the network would diverge. In analytical terms, it is possible to illustrate the learning process of a net with two hidden layers, for which it is therefore necessary to determine the set of parameters $\Omega=\left\{\omega_{\mathrm{k}, \mathrm{i}}, \rho_{\mathrm{l}, \mathrm{k}}, \gamma_{1}\right\}$.

The problem consists of [18] the minimizing of the loss function, defined as the sum of the squares of the differences between the observed data sample $y$ and the prediction of the net $\hat{y}$ :

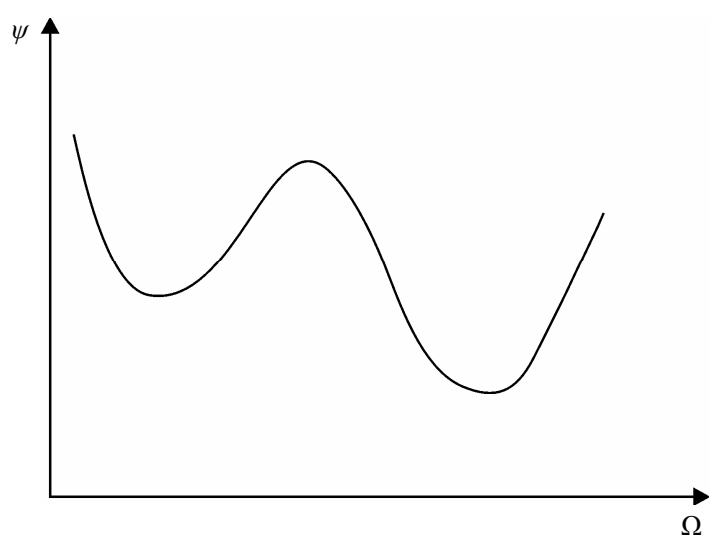

Figure 4. Example of succession of local and global minimums 


$$
\begin{gathered}
\min _{(\Omega)} \psi(\Omega)=\sum_{t=1}^{T}\left(y_{t}-\hat{y}_{t}\right)^{2} \\
\hat{y}_{t}=f\left(x_{t} ; \Omega\right)
\end{gathered}
$$

in which $\mathrm{T}$ is the number of the observations of the output vector $y$, and $f\left(x_{\mathrm{t}} ; \Omega\right)$ represents the neural network. $\Psi$ is a nonlinear function of $\Omega$. All nonlinear optimizations begin with an initial guess about the solution and try further, better solutions until finding the best possible within a reasonable number of iterations. Different methodologies have been proposed in order to lead this search: some make reference to complex results of logical- numerical analysis, e.g. genetic algorithms, in alternative to the classic method of the reduction of the gradient or Newton-Raphson method. In any case the chosen algorithm continues until the last iteration $n$, or in alternative a tolerance criterion can be set up, stopping the iterations when the reduction of the error function comes down a predefined tolerance value. In order to avoid local optimums, a solution could be to determine a first convergence of the process, and then to repeat it with a set of different initial parameters in order to verify whether the solution changes. Alternatively, numerous processes could be carried out to determine the best solution. However, there are the most important problems when the number of the parameters increases or the architecture of the network becomes particularly complex. Paul John Werbos proposed in the beginning of 1970's an alternative to the gradient method called back-propagation method. It is a very flexible method to avoid the problems caused by the evaluation of the Hessian matrix in the reduction of the gradient, and surely it is the most used method. In the passage from an iteration to the successive one in the process of evaluation of the parameters, the inverse Hessian matrix is in fact replaced by an identity matrix having dimension equal to the number $k$ of the parameters, multiplied by the learning coefficient $\rho$ :

$$
\left(\Omega_{1}-\Omega_{0}\right)=-H_{0}^{-1} Z_{0}=-\rho Z_{0}
$$

In order to avoid oscillations this coefficient is chosen in the range $[0.05,0.5]$ and it can also be endogenous, that is it can assume various values when the gradient comes down and the process seems to converge; or finally different coefficients for the various parameters can be adopted. However, the problem of the choice of this coefficient remains, together with the existence of local minimums. Moreover, low values of the learning coefficient, although as anticipated are able to avoid oscillations, can extend uselessly the convergence of the minimizing process. This can however be accelerated adding a 'momentum' for which at iteration $n$ we will have:

$$
\left(\Omega_{n}-\Omega_{n-1}\right)=-\rho Z_{n-1}+\mu\left(\Omega_{n-1}-\Omega_{n-2}\right)
$$

\footnotetext{
5 F. Dolcino, C. Giannini, and E. Rossi, where the concepts of "evaluation error" and "approximation error" are analyzed, 1998.

6 R. C. Merton, 1974; F. Black and J. COX, 1976; F. A. Longstaff and E. Schwartz, 1995; H. E. Lelan and K. B. Toft, 1996; C. Dufresne and R Goldstein, 2001.
}

Therefore, with $\mu$ generally equal to 0.9 , the calculation of the parameters moves more fast outside a plateau in the error surface. Now we will briefly discuss the methods used to estimate the effectiveness of the output of the net. Relatively to the evaluation of the goodness of the predictions of the net, the most common index is R-squared (goodness of fit) especially as far as the capability of the net to predict the data with which it has been trained is concerned, and the root mean squared error (Rmse) as for the capability to generalize the predictions outside the data sample used for the training; in other words, divided the sample into two parts, the first (in sample) will be used in order to train the net, and the other (out of sample), in general equal to about $25 \%$ of total data, will be used to estimate the capability of the net to predict data coming from the same population but not used for the training.

However, as to the total amount of necessary data ${ }^{5}[10]$, undoubtedly a neural network requires the evaluation of many more coefficients than, for example, a linear model, and this leads to the necessity of a wide sample. Surely the availability of wide samples improves the predictive abilities of the net, but it also implies longer training times. Moreover, the availability of a wide sample not always is a positive aspect, especially in the financial field where using very old data brings distortions in the models, because they tend to vary with extreme rapidity and therefore very remote data are no more in any relations with the present ones.

\section{Credit Risk Approach: Our Assumptions}

The recent history of financial markets shows how, to the impetuous development of the financial innovation process, which has invested all the structural components of the same, has been associated the constant engagement of the operators in finding more efficient computational methodologies, able to be an effective dynamic support of the analysis. Growing concerns about credit risk have created the need for sophisticated credit risk analysis and management tools. Credit risk measurement models and credit risk management tools are both of significant importance in the credit market.

The valuation of credit default swap depends on the credit quality of the reference entity. The default prediction has long been an important and widely studied topic. There are two main types of models that attempt to describe default processes in the credit risk literature: structural and reduced form models. The first approach is based on modeling the underlying dynamics of interest rates and firm characteristics and deriving the default probability based on these dynamics ${ }^{6}[1,19,20,21]$. So they use the evolution of firms' structural variables, such as asset and debt values, to determine the time of default. Merton's Model was the first modern model of default and is considered the first structural model. In Merton's model, a firm defaults if, at the time of servicing the debt, its assets are below its outstanding debt. In the second 
approach, instead of modeling the relationship of default with the features of a firm, this relationship is learned from the data. Reduced form models do not consider the relation between default and firm value in an explicit manner $[22,23,24]$. The time of default in intensity models is the first jump of an exogenously given jump process. The parameters governing the default hazard rate are inferred from market data. Structural default models provide a link between the credit quality of a firm and the firm's economic and financial conditions. Thus, defaults are endogenously generated within the model instead of exogenously given as in the reduced approach.

The focus of our model is on the structural approach, pioneered by Merton, with some important integration.

\subsection{A Brief Review of the Structural Approach: Merton's Model}

Merton proposes a simple model of the firm that provides a way of relating credit risk to the capital structure of the firm. The firm has issued two classes of securities: equity and debt. The equity receives no dividends. The debt is a pure discount bond. The value of the firm's assets is assumed to obey a lognormal diffusion process with a constant volatility. Merton adopts are the inexistence of transaction costs, bankruptcy costs, taxes or problems with indivisibilities of assets; continuous time trading; unrestricted borrowing and lending at a constant interest rate r; no restrictions on the short selling of the assets; the value of the firm is invariant under changes in its capital structure (Modigliani-Miller Theorem) and that the firm's asset value follows a diffusion process.

Merton models equity in this levered firm as a call option on the firm's assets with a strike price equal to the debt repayment amount (D). If at expiration (coinciding to the maturity of the firm's short-term liabilities, assumed to be composed of pure discount debt instruments) the market value of the firm's assets (V) exceeds the value of its debt, the firm's shareholders will exercise the option to "repurchase" the company's assets by repaying the debt. However, if the market value of the firm's assets falls below the value of its debt $(\mathrm{V}<\mathrm{D})$, the option will expire unexercised and the firm's shareholders will default. The probability of default (PD) until expiration is set equal to the maturity date of the firm's pure discount debt, typically assumed to be one year. Thus, the Pd until expiration is equal to the likelihood that the option will expire out of the money. To determine the PD, the call option can be valued using an iterative method to estimate the unobserved variables that determine the value of the equity call option, in particular, $\mathrm{V}$ (the market value of assets) and $\sigma_{\mathrm{V}}$ (the volatility of assets). These values for $\mathrm{V}$ and $\sigma_{\mathrm{V}}$ are then combined with the amount of debt liabilities $\mathrm{D}$ that have to be repaid at a given credit horizon in order to calculate the firm's distance to default, defined to be: (V-D)/ $\sigma_{\mathrm{V}}$ or the number of standard deviations between current asset values and the debt repay- ment amount. The higher the distance to default (denoted DD), the lower the PD. To convert the DD into a PD estimate, Merton assumes that asset values are log-normally distributed.

Define $\mathrm{E}$ as the value of the firm's equity and $\mathrm{V}$ as the value of its assets. Let $E_{0}$ and $V_{0}$ be the values of $E$ and $V$ today; in the Merton framework we have:

$$
\begin{gathered}
E_{0}=V_{0} N\left(d_{1}\right)-D e^{-r t} N\left(d_{2}\right) \\
d_{1}=\frac{\ln \left(V_{0} / D\right)+\left(r+\sigma_{V}^{2} / 2\right) T}{\sigma_{V} \sqrt{T}} \\
d_{2}=d_{1}-\sigma_{V} \sqrt{T}
\end{gathered}
$$

where $\sigma_{V}$ is the volatility of the asset value and $r$ is the risk free rate of interest, both of which are assumed to be constant. Define $\mathrm{D}^{*}=D e^{-r t}$ as the present value of the promised debt payment and let $\mathrm{L}=\mathrm{D} * / \mathrm{V}_{0}$ be a measure of leverage. Because the equity value is a function of the asset value we can use Ito's lemma to determine the instantaneous volatility of the equity from the asset volatility:

$$
\begin{gathered}
\sigma_{E} E_{0}=\frac{\partial E}{\partial V} \partial_{V} V_{0} \\
\frac{\partial E}{\partial V}=N\left(d_{1}\right)
\end{gathered}
$$

where $\sigma_{\mathrm{E}}$ is the instantaneous volatility of the company's equity at time zero. These equations allow $\mathrm{V}_{0}$ and $\sigma_{\mathrm{V}}$ to be obtained from $\mathrm{E}_{0}, \sigma_{\mathrm{E}}, \mathrm{L}$ and $\mathrm{T}$. The risk neutral probability, $\mathrm{P}$, that the company will default by time $\mathrm{T}$ is the probability that shareholders will not exercise their call option to buy the assets of the company for D at the time T. This depends only on the leverage, L, the asset volatility, $\sigma$, and the time of repayment $\mathrm{T}$.

\subsection{CDS Valuation}

In our analysis, we present some extensions because the model needs to make the necessary assumptions to adapt the dynamics of the firm's asset value process.

We suggest a new way of implementing Merton's model using implied volatility, instead of historical volatility: this leads to a higher capability of getting the signals launched by the market about the creditworthiness of the firm. The historical volatility is the realized volatility of a financial instrument over a given time period. Generally, this measure is calculated by determining the average deviation from the average price of a financial instrument in the given time period. Standard deviation is the most common but not the only way to calculate historical volatility. By definition, historical volatility will always be backward looking and lag the real-time volatility environment. In the current market environment, however, where both stocks and implied volatility measures are rising, many measures of historical volatility begin to seem no more useful. 
The implied volatility of an option contract is the volatility implied by the market price of the option based on an option pricing model. Implied volatility is a forward-looking measure, and differs from historical volatility that is calculated from known past prices of a security.

\begin{tabular}{ccc}
\multicolumn{1}{c}{ Past } & Present & Future \\
$\begin{array}{l}\text { Historical } \\
\text { Volatility }\end{array}$ & $\begin{array}{l}\text { Theoretical } \\
\text { Price }\end{array}$ & Implied \\
Volatility
\end{tabular}

Historical volatility tells us how volatile as asset has been in the past. Implied volatility is the markets view on how volatile an asset will be in the future. To determine an option's implied volatility, we have to use a pricing model. We can tell how high/low implied volatility is by comparing the market price of an option to the options theoretical fair value. This is why we need to use an option pricing model - to determine the fair value of an option and hence know if the market price for the option is over/under valued.

In our analysis, equity implied volatilities observed in the equity options market has received much exploration. Our neural network model is based on using the implied volatility of one-year options written on the shares issued by the company. It is an attractive alternative to the traditional structural approach; this implementation allows to use a forward-looking model. Otherwise, our model differs from the structural approach for the fact that it consider the 30-month historical series for CDS spreads: we show that the use of these credit spreads in addition to other inputs, provides a significant improvement in the accuracy of the model.

We use a model that takes these inputs:

- Leverage of the firm: the level of indebtedness is a significant enterprise-specific determinant of risk.

- Implied volatility: theoretical value designed to represent the volatility of the security underlying an option as determined by the price of the option. The factors that affect implied volatility are the exercise price, the risk-free rate, the maturity date and the price of the option.

- Historical CDS spreads serie: a CDS is a derivative that protects the buyer against default by a particular company. The CDS spread is the amount paid for protection and is a direct market-based measure of the company's credit risk. CDS spreads contain information which is significant for estimating the probabilities of the occurrence of credit events.

- Recovery rate: percentage of notional of the reference asset repays in the event of default.

- Risk free rate: is the interest rate that it is assumed can be obtained by investing in financial instruments with no default risk.

\section{Data and Empirical Results}

In this section the potentialities of neural networks in the approximation of the pricing of credit derivatives will be shown using real market data, collected from Fitch ${ }^{\mathrm{TM}}$ and Bloomberg ${ }^{\mathrm{TM}}$ data bases.

Starting from September 2002, we have collected on a quarterly basis data regarding 5-year maturity CDS spreads of 18 companies from various economic sectors, together with data concerning the leverage of the firms, the implied volatility of 1-year maturity call options written on the equities of the firms, and the risk free rate assumed to be equal to the 1-year constant maturity Treasury Bill yield. As regards the recovery rate, we have used the most commonly values adopted by the operators to price CDS, depending on the economic sector to which the reference entity belongs to. In the following diagrams we show the sample collected until March 2006, therefore covering 14 quarters.

As regards the risk free rate, we must consider that a portfolio made up of a risky bond with yield equal to $i$ and a CDS written on it with a spread equal to $s p$ is virtually free of any credit risk, so its yield must be equal to the risk free rate; therefore we have the following approximation:

Table 1. Details of the companies included in the sample

$\begin{array}{rllr}\text { N } & \text { Ticker } & \text { Name } & \text { Sample description } \\ 1 & \text { AA } & \text { ALCOA Inc. } & \text { Market Cap. (bln \$) } \\ 2 & \text { BA } & \text { Boeing Company (The) } & 30,18 \\ 3 & \text { CCL } & \text { Camival Corporation } & 71,91 \\ 4 & \text { COX } & \text { Cox Communications Inc. * } & 30,13 \\ 5 & \text { CTX } & \text { Centex Corporation } & 5,9 \\ 6 & \text { CVS } & \text { CVS Corporation } & 6,15 \\ 7 & \text { CZN } & \text { Citizens Communications Corporation } & 26,96 \\ 8 & \text { FD } & \text { Federated Department Stores Inc. } & 4,81 \\ 9 & \text { GPS } & \text { Gap, Inc. (The) } & 23,16 \\ 10 & \text { IBM } & \text { International Business Machines Corporation } & 16,23 \\ 11 & \text { JPM } & \text { JPMorgan Chase \& Co. } & 149,11 \\ 12 & \text { JWN } & \text { Nordstrom Incorporated } & 177,41 \\ 13 & \text { LEH } & \text { Lehman Brothers Holdings Inc. } & 15,03 \\ 14 & \text { LEN } & \text { Lennar Corporation } & 43,46 \\ 15 & \text { MAR } & \text { Marriott International, Inc. } & 6,74 \\ 16 & \text { MCD } & \text { McDonald's Corporation } & 19,51 \\ 17 & \text { SBC } & \text { AT\&T Inc. } & 56,05 \\ 18 & \text { TXT } & \text { Textron Financial Corporation } & 233,83 \\ \text { * Company was delisted on December, 9th 2004. This fact does not affect in any way our results. } & 12,21\end{array}$

Risk-free rate

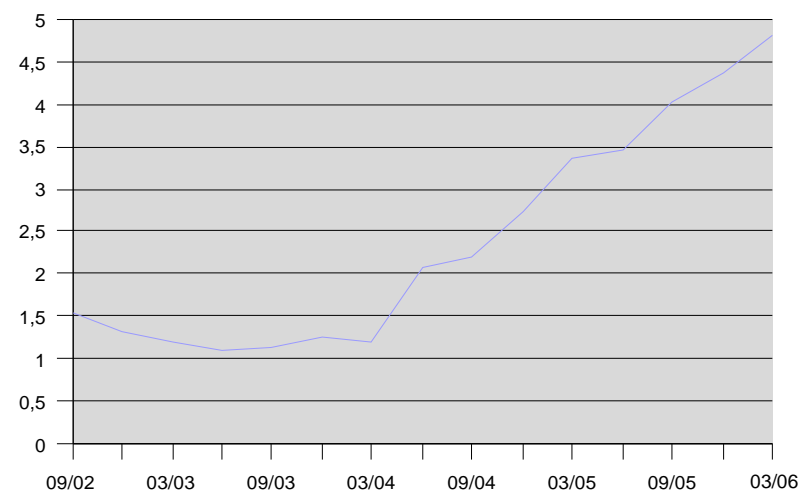

Figure 5. Risk free rate during our study (Source: Federal Reserve System) 
Table 2. Recovery rates (Source: Altman and Kishore (1996))

Economic sector

Hotel chains

Department stores

Finance

Telecommunications

Constructions

Metal and mechanic

Food

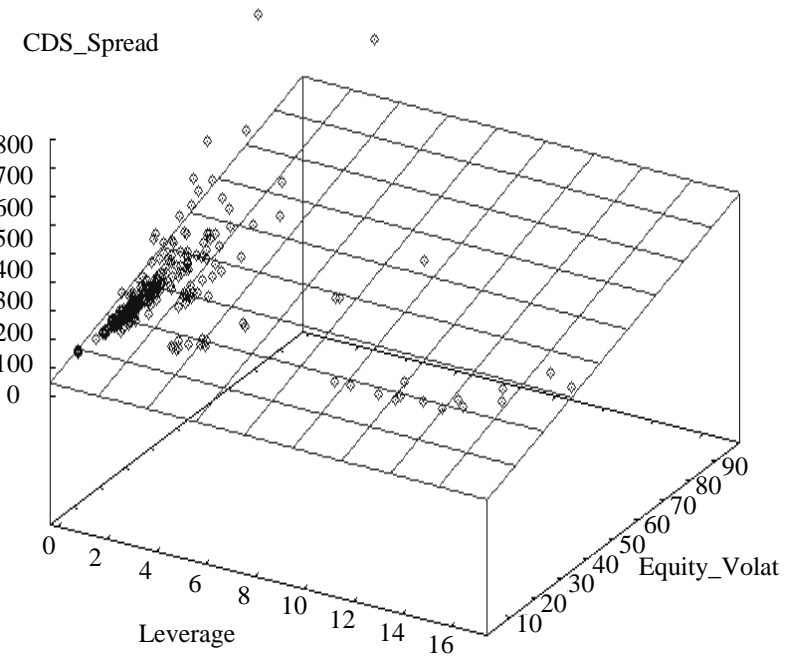

Figure 6. Relationship between CDS Spread, Leverage and Equity volatility in our sample (Source: our elaborations)

$$
r_{f}=i-s p
$$

showing an inverse relationship between $s p$ and $r f$, confirmed by market data. We have the following correlation values:

Source: our elaborations

\begin{tabular}{lc}
\hline \multicolumn{1}{c}{ Variable } & Correlation with CDS Spread \\
\hline Risk-free (Rf) & $-0,2187$ \\
Recovery rate (R) & $-0,1475$ \\
Leverage (L) & $-0,0485$ \\
Equity volatility (V) & 0,6338 \\
\hline
\end{tabular}

Of course we can notice a negative correlation with $R$ (the recovery rate) and a strong positive correlation with $V$ (the implied volatility which in our study proves to be very effective in predicting creditworthiness deterioration). The absence of a correlation with the leverage should not seem strange: our sample in fact includes financial companies too, which typically have a very high gearing ratio and a low CDS spread due to prudential regulation: in any case the neural network can solve this problem very well because of its nonparametric capabilities. Without considering the financial firms, the correlation of leverage and credit spreads would rise to 0.317 .

The sample is made up of companies coming from different economic sectors, as it is easy to catch reading the recovery rates applied: of course we consider only big (or at least medium)-caps, the only ones for which a liquid market for CDS exists. In Figure 6 we show the relationship between CDS spread, Leverage and Equity volatility. It is evident that there is no linear relation between them. Moreover, only a few data are characterized by a leverage of more than 2: of course these can only be banks, which for prudential regulation can have a high gearing ratio. In the following part we will show how neural networks are able to price both industrial and financial firms at the same time, even if they show a strongly different leverage.

We have used a feed forward neural network, with the back propagation algorithm; it is a 4-layer network, with two hidden layers and therefore an output layer of only one node (the CDS spread).

The input layer consists of 18 nodes: in the first four nodes we have the risk free rate, the recovery rate, the leverage and the implied volatility of the firm; in the remaining 14 nodes we have the series of quarterly CDS spreads of the firm. If there is a lack in the data, we just use the value of the preceding quarter. This approach merges data coming from the firm with data (the CDS spreads) coming from the market, giving great effectiveness to the predictions of the network. Moreover the power of this approach can be appreciated observing that in this way the network is able to price CDS with reference entities coming both from the industrial field (which usually have low leverages and high CDS spreads) and from the financial field (which have an extremely high gearing ratio but are characterized by a history of low CDS spreads because of the prudential regulation, using this detail to discriminate between them). Figure 7 shows the structure of the network. The sample has of course been shuffled; the learning parameter has been settled to 0.5 and the initial parameters of the neurons have been chosen in the range [-2,2]. Our study shows that a logarithmic reduction is more efficient, because our sample consists of extremely variable data, so a simple linear reduction would enhance the distortions brought by the so- called outliers, that is data very different from the rest of the sample.

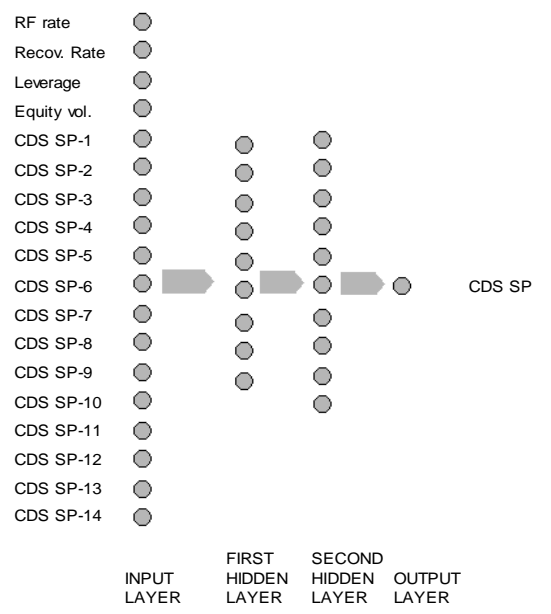

Figure 7. Structure of the neural network (Source: our elaborations) 
BOEING COMPANY

$\mathrm{ACF}$
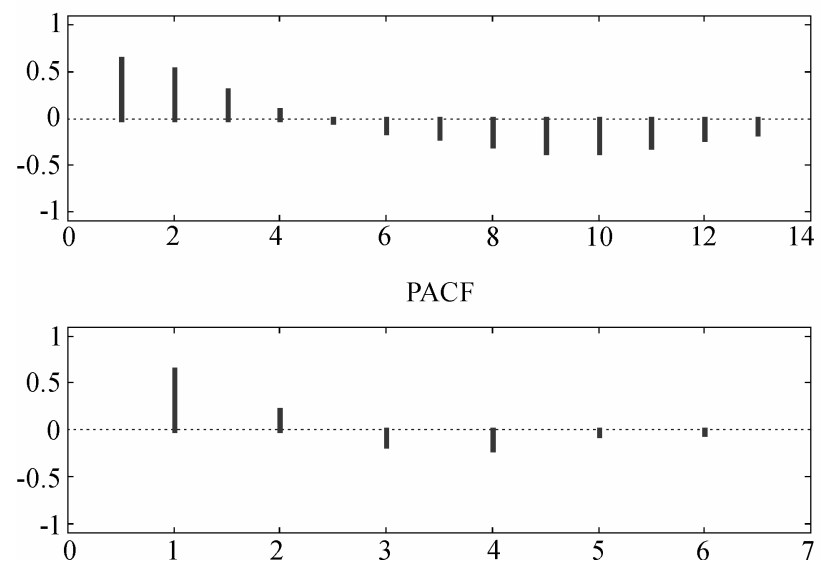

Figure 8. Typical correlogram of a CDS spread time serie (Source: our elaborations)

In Figure 8 we show as an example the correlogram for the CDS spread time series of The Boeing Company only, for the sake of simplicity, but we obtained the same structure for all the companies included in our sample: in the first part we can see the correlation between each value and a delayed value (the delay being expressed on the $\mathrm{x}$-axis); the second part shows the correlation between each value and $p$ preceding values, with $p$ on the $\mathrm{x}$-axis. It is therefore evident that the correlation between values, even if decreasing, is strong, so the series is autoregressive; we can then express each value in terms of the preceding ones. In this sense a CDS spread is more similar to an interest rate than to an equity price, so that it shows a mean reversion process which tends to pull spreads higher (lower) than some long-run average level back to this value over time. Obviously we shall have a negative (positive) drift. The sinusoidal cycle observable in the correlogram explains this phenomenon: moreover, it is a consequence of the strict relationship between CDS spreads and risk-free interest rates already discussed [25].

Figure 9 showing in red the neural network predictions and in yellow the real market data, confirms the effectiveness of the neural network in predicting CDS spreads.

In Table 3 and 4 the values of $R$-squared and Rmse are shown: as it is easy to observe, the results are highly coherent. We compare the results from or implementation with another model: Creditgrades ${ }^{\mathrm{TM}}$. We must stress the point that using traditional models such as Creditgrades $^{\mathrm{TM}}$ we would obtain predictions almost useless, even excluding banks from the sample; neural networks surely are a great pricing instrument in order to evaluate credit spreads. The architecture of the neural network is feed forward, trained for 17000 learning epochs using the back propagation algorithm. Therefore it turns out obvious that neural networks are able to totally capture the variability relative to the market dynamics of credit derivatives: because of the fact that in literature there is no unanimity on the determination of the form of the CDS spread evaluation function, neural networks can therefore be seen as effective instruments of elaboration able to satisfy this lack from a statistical point of view.

Figure 10 shows a "delta" for a CDS contract: in fact we find on the $\mathrm{x}$-axis the leverage, and on the $\mathrm{y}$-axis the values calculated with the finite differences method, that is:

$$
\Delta=\lim _{h \rightarrow 0} \frac{S P(l e v+h)-S P(l e v)}{h}
$$

In a similar manner we can calculate for a CDS all the "greek" letters typical of derivative contracts using the outputs of the neural network with $h-10^{-6}$. It is evident in

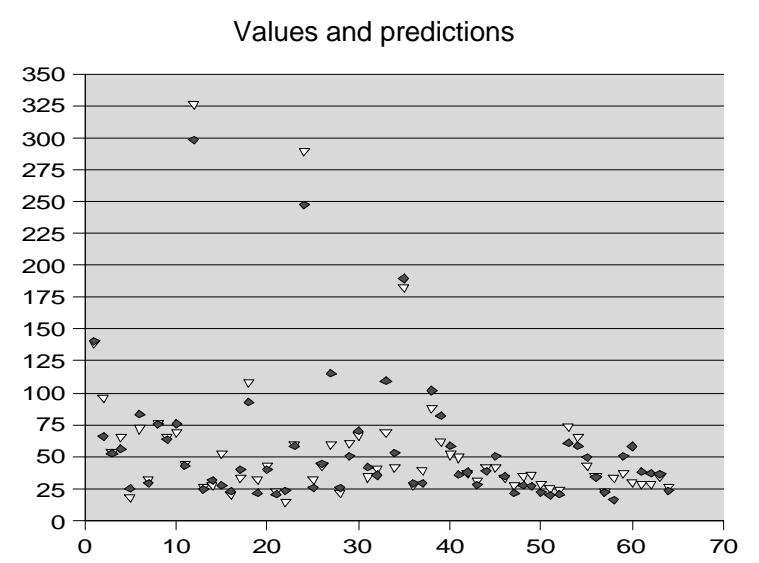

Figure 9. Market data (in yellow) and predictions of the neural network (in red) (Source: our elaborations)

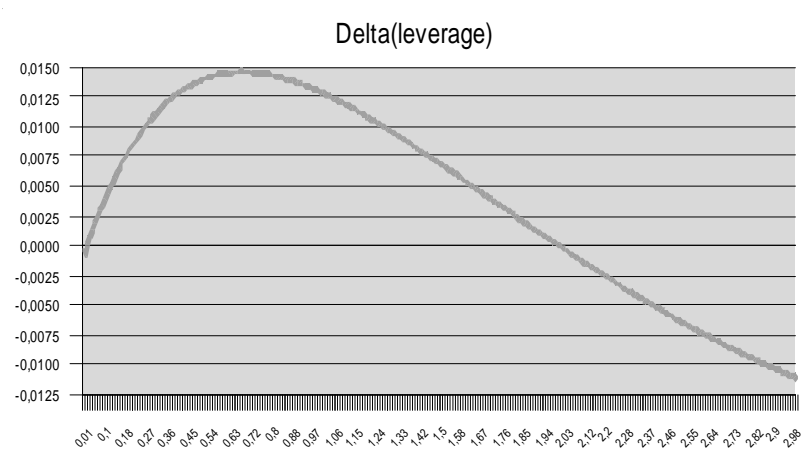

Figure 10. Relationship between delta and leverage (Source: our elaborations)

Table 3. Approximation of the neural network (Source: our elaborations)

\begin{tabular}{lc}
\hline \multicolumn{1}{c}{ Error } & Value \\
\hline R-squared & 0,9082 \\
Root mean squared error & 14,3988 \\
\hline
\end{tabular}

Table 4. Comparing statistical results (Source: our elaborations)

\begin{tabular}{cccc}
\hline & $\mathrm{NN}$ & Credit Grades & Linear regression \\
\hline Correlation & 0,9636 & $-0,02$ & 0,9309 \\
Rmse & 14,3988 & $>100$ & 30,86 \\
R-square & 0,9086 & $>1$ & 0,8566 \\
\hline
\end{tabular}


Figure 10 shows a "delta" for a CDS contract: in fact we find on the $\mathrm{x}$-axis the leverage, and on the $\mathrm{y}$-axis the values calculated with the finite differences method, that is:

$$
\Delta=\lim _{h \rightarrow 0} \frac{S P(l e v+h)-S P(l e v)}{h}
$$

In a similar manner we can calculate for a CDS all the "greek" letters typical of derivative contracts using the outputs of the neural network with $h-10^{-6}$. It is evident in the diagram that for high leverages "delta" becomes negative: in fact we must remember that highly leveraged companies belong usually to the financial sector, so that they are less risky because of the prudential regulation. This effect is explained very well by the network, in fact for low leverages (typical of the industrial field) we see a direct relationship between leverage and CDS spreads. In other words, the neural network is able to recognize the risk of the activity carried out by the company using the time series of its CDS spread: in the part of our study covering the correlation, we obtained an average value for each observation and the preceding one of 0.90 , as it is evident from the correlogram shown above. This correlation, along with the part regarding the independent variables, typical of the structural approach, explains the major part of the variability of CDS spreads.

\section{Conclusions and Future Work}

In this paper we have discussed an innovative approach to the study of CDS valuation, using neural networks. Our analysis is based on modeling the underlying dy

Vega(vol)

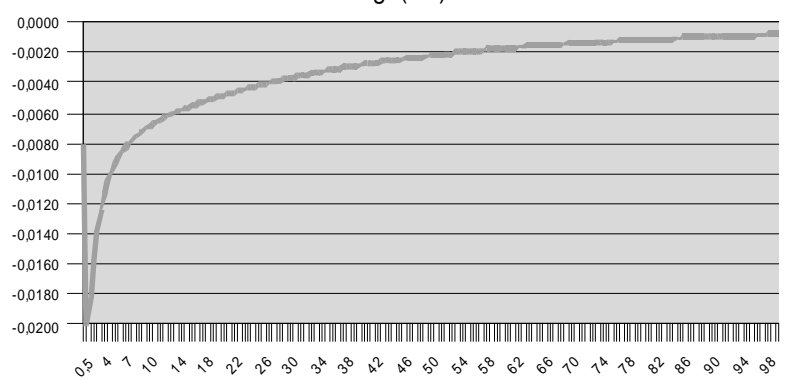

Figure 11. Relationship between vega and equity volatility (Source: our elaborations)

Gamma (leverage)

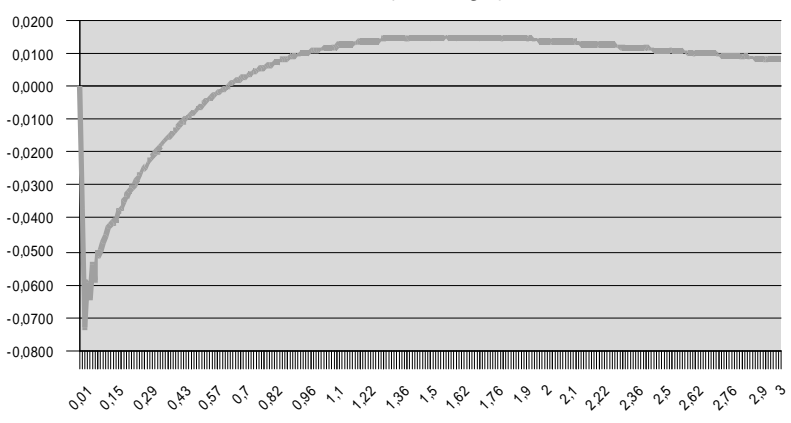

Figure 12. Relationship between gamma and leverage (Source: our elaborations)

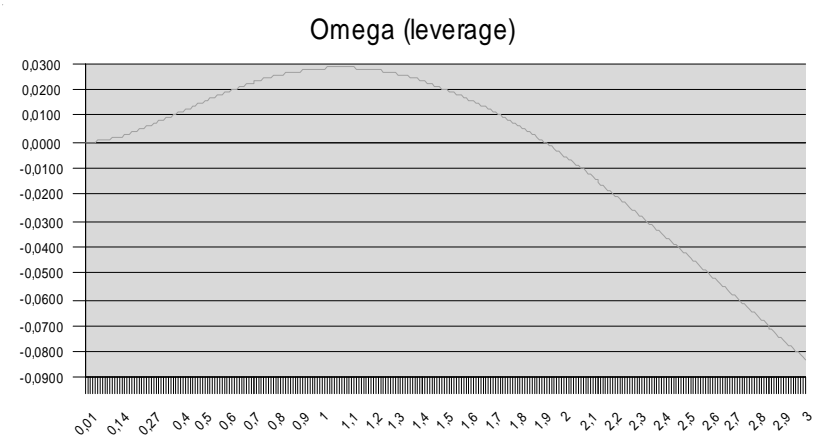

Figure 13. Relationship between omega and leverage (Source: our elaborations)

namics of interest rates and firm characteristics and deriving the default probability based on these dynamics (the structural approach).

The model that we propose is peculiar for the use of the implied volatility of one-year options written on the shares of the analyzed companies, instead of historical volatility. Besides, the model differs from the structural approach for the fact that it considers the 30-month historical series for CDS spreads, including additional market variables. This implementation allows to use a forward-looking model and to capture the dynamic behavior of CDS spreads and equity volatility. This approach merges data coming from the firm with data (the CDS spreads) coming from the market, giving great effectiveness to the predictions of the neural network. Moreover, the power of this model can be appreciated observing that in this way the network is able to price CDS with reference entities coming both from the industrial field (which usually have low leverages and high CDS spreads) and from the financial field (which have an extremely high gearing ratio but are characterized by a history of low CDS spreads because of the prudential regulation, using this detail to discriminate between them).

We find that the neural network technique is useful for analyzing the pricing of a credit default swap. Our model produces a much lower forecasting error than those traditional models, such as Creditgrades ${ }^{\mathrm{TM}}$, indicating a relatively high precision in the neural network prediction. In particular, in the last part, starting from the high correlation observed between each CDS spread value and the preceding one in the time series of each company, we have trained a neural network based both on these time series and on the structural details of the firms, that is leverage, option-implied equity volatility and recovery rates. Our results in terms of $R$-squared and Rmse are highly coherent and are confirmed by the empirical data.

Our analysis presents the results that we have achieved and shows that the neural network model offers an alternative to traditional methodologies to deal with complicated issues related to CDS valuation.

Anyway, in this period, the CDS market is particularly volatile. The impact on the economy of the deflating 
housing bubble, the credit crisis in general, have stoked fear about increasing corporate defaults. This crisis is about credit risk. A credit bubble has ballooned for years, being enhanced by the existence of CDS. As credit originators can pass their risk to other agents, they have been less careful about the quality of their loans. In that sense, CDS have given an incentive for distributing more credit to more risky borrowers. As banks and all financial institutions and companies have committed themselves in the CDS market, they are now highly dependent on market continuity and on its smooth functioning. The failure of a major participant (bankruptcies of Bear Sterns, then those of AIG and Lehman Brothers) can put at stake all the others; the faith in the reliability of the market has been deeply shaken by these events.

In any case, some aspects of the proposed evaluation methodology require additional research: the possible next step for the research community is to improve the models in the case of catastrophic circumstances (the so-called LFHI (low frequency-high impact) events); another interesting case of study would regard the analysis of the recent financial crisis when more reliable information regarding financial companies will be available.

\section{REFERENCES}

[1] R. C. Merton, "On the pricing of corporate debt: The risk structure of interest rate," The Journal of Finance, 291974.

[2] S Henke, H. P. Burghof, and B. Rudolph, "Credit securitization and credit derivatives: Financial instruments and the credit risk management of middle market com-mercial loan portfolios", CFS Working paper $\mathrm{Nr}$, July 1998.

[3] A. Greenspan, "Economic flexibility," Speech to HM Treasury Enterprise Conference, London, UK, 2004.

[4] S. DAS, "Credit derivatives: Trading \& Management of Credit \& Default Risk," John Wiley \& Sons, Chicago, 1998.

[5] J. M. Tavakoli, "Credit derivatives: A guide to instruments and applications," John Wiley \& Sons, Chicago, 1998.

[6] G. R. Duffee and C. Zhou, "Credit derivatives in banking: useful tools for managing risk?" Journal of Monetary Economics, No. 48, 2001.

[7] R. Stultz, "Risk management and derivatives," SouthWestern Publishing, 2003.

[8] B. A. Minton, R. Stultz, and R.Williamson, "How much do bank use credit derivatives to reduce risk?" Working Papers, 2005.
[9] Bank for international settlement, "International convergence of capital measurement and capital standards," Basel Committee on Banking Supervision, A Revised Framework, Update November 2005.

[10] F. Dolcino, C. Giannini, and Rossi, E, "Reti neurali artificiali per l'analisi e la previsione di serie finanziarie," Collana studi del Credito Italiano, 1998.

[11] D. Floreano and S. Nolfi, "Reti neurali: algoritmi di apprendimento, ambiente di apprendimento, architettura," in Giornale Italiano di Psicologia, a. XX, pp. 15-50, febbraio 1993.

[12] M. Gori, "Introduzione alle reti neurali artificiali," in Mondo Digitale n. 4, AICA, settembre 2003.

[13] C. Wu and C. H.Yu, "Risk aversion and the yield of corporate debt," in Journal of Banking and Finance, No. 20, 1996.

[14] C. $\mathrm{Wu}$, "A certainty equivalent approach to municipal bond default risk estimation," in Journal of Financial Research, 1991.

[15] P. D. Mcnelis, "Neural networks in finance," Elsevier Academic Press, 2005.

[16] A. Beltratti, M. Serio, and P. Terna, "Neural networks for economic and financial modelling," International Thomson Computer Press, 1996.

[17] S. Hykin, "Neural networks: A comprehensive foundation," Prentice Hall International, 1999.

[18] P. Werbos, "Backpropagation, past and future," in Proceedings of the IEEE International conference on neural networks, IEEE press, 1988.

[19] F. Black and J. Cox, "Valuing corporate securities: Some effects of bond indenture provisions," Journal of Finance, pp. 31, 1976.

[20] H. E. Lelan and K. B. Toft, "Optimal capital structure, endogenous bankruptcy, and the term structure of credit spreads," The Journal of Finance, pp. 51, 1996.

[21] Collin dufresne and P. R. Goldstein, "Do credit spreads reflect stationary leverage ratios," Journal of Finance, pp. 52, 2001.

[22] R. A. Jarrow and S. M. Turnbull, "Pricing derivatives on financial securities subject to credit risk," The Journal of Finance, pp. 50, 1995.

[23] R. Jarrow, D. Lando, and S. Turnbull, “A markov model for the term structure of credit spreads," Review of Financial Studies, pp. 10, 1997.

[24] D. Duffie and K. J. Singleton, (1998), "Modelling term structures of defaultable bonds," Review of Financial Studies, pp. 12, 1999.

[25] J. C. Hull, "Opzioni, futures e altri derivati," Il Sole 24Ore S. p. A., 2003.

(Edited by Vivian and Ann) 